\title{
OBJECTIVE TREATMENT RESPONSE TO ENDOCRINE THERAPY IN METASTATIC PROSTATE CANCER
}

\author{
MICHAEL R. ZARAGOZA, M.D. \\ H. BARTON GROSSMAN, M.D.
}

From the Department of Surgery, Section of Urology, University of Michigan, Ann Arbor, Michigan

\begin{abstract}
A ten-year review of 198 patients with Stage D2 prostate cancer identified 13 patients (6.6\%) who exhibited objective responses to hormonal treatment, as indicated by regression of a positive bone scan, CT scan, or chest $x$-ray film. Four patients had complete responses and 9 patients achieved partial responses as judged by the National Prostatic Cancer Project criteria. Median survival for those with objective treatment response has not yet been reached (>44 months) compared with twenty-four months for the nonresponders $(p=0.00006)$. Although relatively uncommon, objective treatment response in Stage D2 prostate cancer is correlated with an improved prognosis.
\end{abstract}

Since the early 1940s, hormonal therapy has been the standard of treatment for metastatic prostate cancer. Yet, little is known about objective treatment response and its relation to prognosis. In the Veterans Administration Cooperative Urologic Research Group (VACURG), Bayard and associates ${ }^{1}$ reported that 10 percent of patients treated with endocrine therapy alone lived longer than ten years. It appears that the natural history of prostate cancer is variable and probably includes a subset of patients whose response to hormonal treatment is unusually favorable. In an attempt to identify this patient group, we report our experience with hormonally treated patients with Stage D2 prostate cancer over a ten-year period.

\section{Material and Methods}

We reviewed the charts of 198 patients with Stage D2 prostate cancer (extrapelvic metastasis) treated with hormonal therapy at the University of Michigan Hospital from January 1981 to January 1991. Patient ages ranged from thirty-three to eighty-five years, with a median of 64.5 years. All patients had biopsy-proved prostate adenocarcinoma and evidence of Stage
D2 disease on bone scan, computerized tomography (CT) scan, or chest x-ray film. The majority of patients (136) presented initially with distant spread, while the remainder (62) progressed to advanced disease after unsuccessful treatment for localized cancer. Each received hormonal treatment when distant metastasis was apparent. Hormonal therapy included single agent or combination treatment with estrogens, LHRH agonists, flutamide, or bilateral orchiectomy. Follow-up radiographic studies were analyzed after initiation of treatment.

Patients were evaluated for response using the criteria of the National Prostatic Cancer Project (NPCP). ${ }^{2}$ Criteria for a complete response (CR) included all of the following: (1) tumor masses which completely disappear, (2) normalization of acid phosphatase, (3) disappearance of osteolytic or osteoblastic lesions, (4) normalization of liver size or liver function tests, and (5) absence of new symptoms. Criteria for a partial response (PR) included any of the following: (1) recalcification of osteolytic lesions, (2) a 50 percent reduction in bone scan uptake or cross-sectional area of measurable lesions, (3) a 30 percent reduction in liver size or 
Figure 1. Bone scan demonstrating resolution of bony metastases (Pt. 2). (A) Prior to orchiectomy; (B) thirteen months postoperatively.
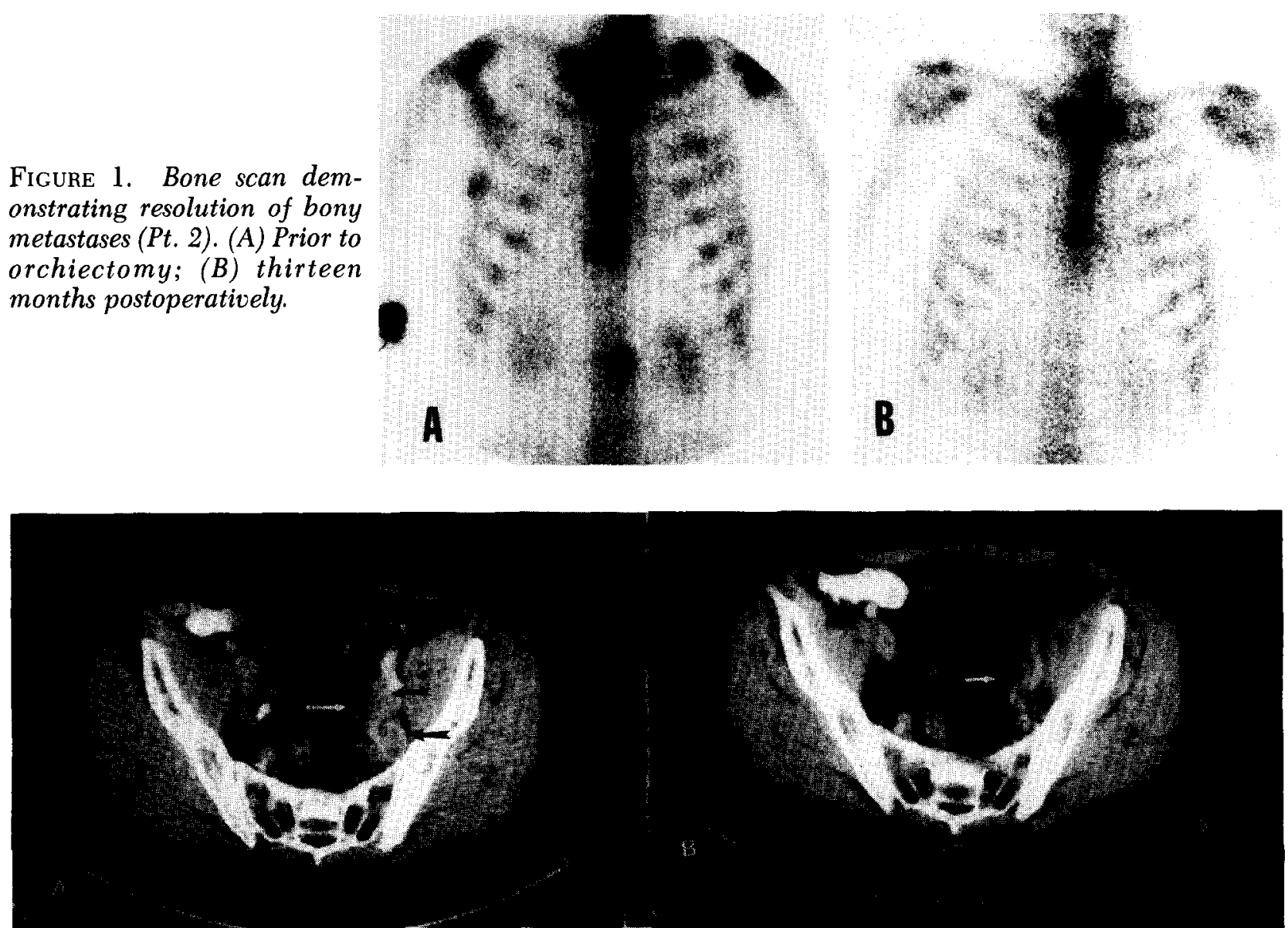

Figure 2. Response of lymphatic metastases to endocrine therapy (Pt. 9). (A) Pelvic CT (12/29/82) demonstrating a dilated left ureter (white arrow) and enlarged left pelvic lymph nodes (black arrows). Bilateral orchiectomy was performed January 3, 1983. (B) CT (5/3/83) demonstrating a marked decrease in the size of the lymphatic metastases. (C) $C T(10 / 18 / 83)$ showing resolution of the hydroureter. Reproduced with permission from Grossman $H B$ : Hormonal therapy of prostatic carcinoma: is there a rationale for delayed treatment?, Urology 27: 199 (1986).

liver function tests, along with (4) normalization of acid phosphatase, and (5) absence of new symptoms or new sites of disease. In addition, all responders (complete and partial) had normalization of prostate-specific antigen (PSA) when measured.

\section{Results}

Of the 198 paticnts, $13(6.6 \%)$ exhibited an objective treatment response documented by regression of a positive bone scan, CT scan, or chest X-ray film (Figs. 1 and 2). Four patients had a complete response and 9 had a partial response as judged by criteria of the National

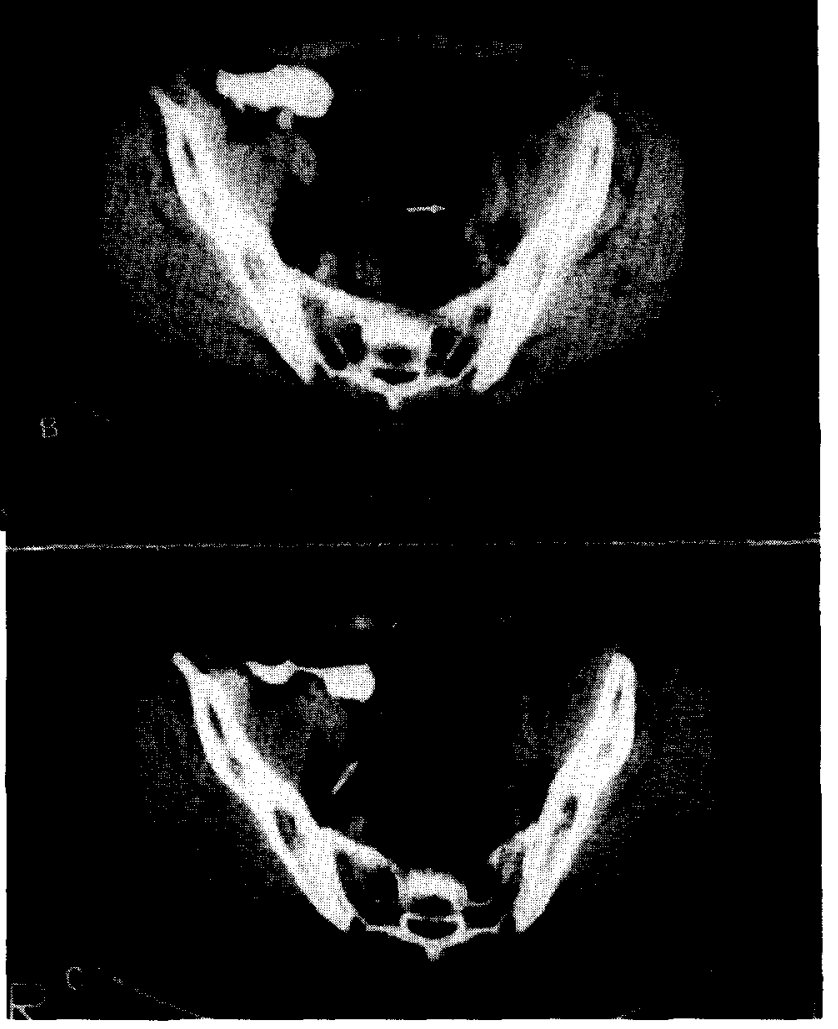

Prostatic Cancer Project (Table I). Treatment response did not appear to be related to the method of hormonal ablation. Characteristics of the 13 responders included a mean age of 63.1 years and a Gleason score ranging from 5 to 9 with a median of 7 . The nonresponder group included 185 patients with a mean age of 64.7 years. Pathology reports were available for 169 of these patients. The median Gleason score for the nonresponder group was also 7 .

Of the responders, 5 patients initially presented with locoregional disease. Two of these patients presented initially as Stage B and were treated with radiation. One patient with Stage $\mathrm{C}$ disease underwent a radical prostatectomy. 


\begin{tabular}{|c|c|c|c|c|c|c|c|c|}
\hline Pt & Age & $\mathrm{Dx}$ & Mets & Site & Treatment & Response & $\begin{array}{l}\text { Duration } \\
\text { (Mos) }\end{array}$ & Status \\
\hline 1 & 69 & $2 / 86$ & $7 / 88$ & Lungs & $\begin{array}{l}\text { PLND } 3 / 86 \\
\text { XRT } 9 / 86 \\
\text { DES } 9 / 88 \\
\text { Orch. } 9 / 88\end{array}$ & $(-)$ CXR 10/88 & 31 & $\overline{\text { Alive-CR }}$ \\
\hline 2 & 78 & $12 / 88$ & $12 / 88$ & Bone & Orch. 1/89 & ( - ) bone scan $2 / 90$ & 27 & Alive-CR \\
\hline 3 & 45 & $12 / 88$ & $12 / 88$ & Retroper. & Orch. $1 / 89$ & (-) CT retroper. & 25 & Alive-CR \\
\hline 4 & 48 & $4 / 89$ & $4 / 89$ & SC node & $\begin{array}{l}\text { XRT } 5 / 89 \\
\text { Orch. } 6 / 90\end{array}$ & (-) SC node $9 / 90$ & 22 & Alive-CR \\
\hline 5 & 59 & $9 / 77$ & $10 / 77$ & Bone & $\begin{array}{l}\text { DES 11/77 } \\
\text { Chemo. } 8 / 85 \\
\text { Chemo. } 2 / 86\end{array}$ & $(-)$ bone scan $4 / 81$ & 108 & Dead-PR \\
\hline 6 & 62 & $5 / 83$ & $5 / 83$ & Bone & $\begin{array}{l}\text { DES } 5 / 83 \\
\text { Lupron } 9 / 89\end{array}$ & $\downarrow$ bone scan $2 / 84$ & 90 & Alive-PR \\
\hline 7 & 57 & $3 / 85$ & $3 / 85$ & Bone & $\begin{array}{l}\text { XRT } 4 / 85 \\
\text { DES } 6 / 85\end{array}$ & $(-)$ bone scan 11/86 & 72 & Alive-PR \\
\hline 8 & 61 & $8 / 86$ & $8 / 86$ & $\begin{array}{l}\text { Bone } \\
\text { mediast. } \\
\text { retroper. }\end{array}$ & $\begin{array}{l}\text { DES } 7 / 86 \\
\text { Lupron } 1 / 90\end{array}$ & $\begin{array}{l}\downarrow \text { bone scan } 4 / 90 \\
\downarrow \text { CT mediast. retroper. } \\
\text { lymph nodes } 3 / 87\end{array}$ & 53 & Alive-PR \\
\hline 9 & 68 & $10 / 82$ & $10 / 82$ & $\begin{array}{l}\text { Retroper. } \\
\text { bone }\end{array}$ & $\begin{array}{l}\text { Orch. 1/83 } \\
\text { Chemo. 5/85 }\end{array}$ & $\begin{array}{l}(-) \text { CT retroper. } 10 / 83 \\
\downarrow \text { bone scan } 6 / 85\end{array}$ & 50 & Dead-PR \\
\hline 10 & 64 & $7 / 87$ & $6 / 88$ & Bone & $\begin{array}{l}\text { XRT } 8 / 87 \\
\text { Orch. } 7 / 88 \\
\text { Lupron } 7 / 89\end{array}$ & $\begin{array}{l}\downarrow \text { bone scan } 12 / 88 \\
(+) \text { bone scan } 7 / 89\end{array}$ & 43 & Alive-PR \\
\hline 11 & 69 & $7 / 87$ & $7 / 87$ & $\begin{array}{l}\text { Bone } \\
\text { SC node }\end{array}$ & Orch. $12 / 87$ & $\begin{array}{l}\downarrow \text { bone scan } 4 / 88 \\
\downarrow \text { SC node } 4 / 88\end{array}$ & 41 & Alive-PR \\
\hline 12 & 67 & $10 / 87$ & $12 / 88$ & Bone & $\begin{array}{l}\text { XRT } 11 / 89 \\
\text { Orch. } 12 / 88\end{array}$ & $\downarrow$ bone scan $7 / 89$ & 27 & Alive-PR \\
\hline 13 & 73 & $12 / 87$ & $2 / 90$ & Bone & $\begin{array}{l}\text { RRP } 3 / 88 \\
\text { XRT } 6 / 88 \\
\text { Orch. } 3 / 90\end{array}$ & $\downarrow$ bone scan $10 / 90$ & 13 & Alive-PR \\
\hline
\end{tabular}

KEY: PLND = pelvic lymph node dissection; XRT = x-ray therapy; DES = diethylstilbestrol; orch. = orchiectomy; chemo. = chemotherapy; $\mathrm{RRP}=$ radical prostatectomy; retroper. = retroperitoneum; mediast. = mediastinum; $\mathrm{SC}=$ supraclavicular; $\mathrm{CR}=$ complete response; $\mathrm{PR}=$ partial response.

Two patients were confirmed Stage Dl by pelvic lymph node dissection and received radiation. The remaining 8 patients in the responder group were diagnosed initially with Stage D2 disease. In all cases, patients received hormonal therapy when progression to Stage D2 was apparent. Sites of metastatic lesions in the responder group included bone in 10 patients, retroperitoneum or mediastinum in 3 patients, supraclavicular nodes in 2 patients, and lungs in 1 patient.

Of the 13 hormonal treatment responders, 2 patients died at fifty months and one hundred eight months, respectively, for a mean survival of seventy-nine months. The 11 responders still alive have a median survival to date of thirtyone months. For the hormonal treatment nonresponders, median survival of the 107 expired patients was eighteen months. The remaining 78 living patients have been followed for a median of twelve months.
Kaplan-Meier survival estimates show a significant difference between the nonresponder curve and the responder curve (Fig. 3) with $\mathrm{p}=0.00006$. Median survival for the nonresponders is twenty-four months, which is similar to other reported data in Stage D2 disease. ${ }^{3.4}$ However, those patients with an objective treatment response have a median survival which has not yet been reached.

\section{Comment}

Metastatic prostate cancer has been traditionally treated with androgen deprivation. Fifty years ago, Huggins and Hodges ${ }^{5}$ introduced castration and estrogen therapy as alternative forms of hormonal treatment. $\mathrm{Al}$ though once widely prescribed, diethylstilbestrol is now used less frequently because of its associated cardiovascular complications and the development of other medical agents not associated with cardiovascular morbidity, e.g., 


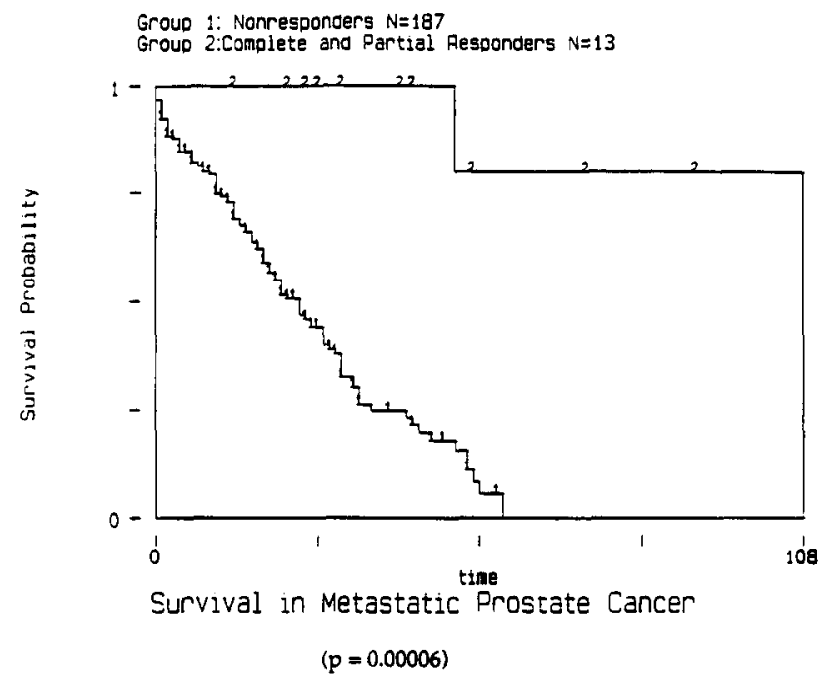

Figure 3. Kaplan-Meier survival curves, responders vs nonresponders (time in months).

luteinizing hormone-releasing hormone (LHRH) agonists and antiandrogens. Numerous studies have demonstrated the LHRH agonists to be equivalent to orchiectomy or DES as initial treatment of advanced prostate cancer. $^{6,7}$ Flutamide, a synthetic nonsteroidal antiandrogen, may be beneficial in combination with the LHRH agonists. ${ }^{8}$

Median survival in Stage D2 prostate cancer patients treated with hormonal therapy is well documented and is generally reported at twenty-four to thirty months. ${ }^{3,4}$ Approximately 80 percent of patients will respond initially to hormonal ablation, suggesting that most prostate cancer cells are androgen sensitive. ${ }^{9}$ Because relapse following an initial response to hormonal manipulation is common, the hypothesis has been proposed that most prostatic carcinomas are heterogeneous and are composed of both androgen-dependent and androgen-independent cells. ${ }^{10-12}$ Androgen withdrawal presumably depletes the androgen-dependent cells. However, eventual replacement by androgen-independent cells frequently occurs, resulting in ultimate treatment failure.

As seen in the VACURG study, the time interval to failure is variable and includes a subset of patients who demonstrate a durable response to hormonal treatment. This translates into prolonged survival which we hypothesized would correlate with objective treatment response. We identified 13 of 198 patients $(6.6 \%)$ who exhibited objective treatment response by NPCP criteria. When compared with hormonal treatment nonresponders over the same time period, a striking survival advantage was seen. Using Kaplan-Meier estimates, a statistically significant difference was apparent between the responder and nonresponder group $(\mathrm{p}=$
$0.00006)$. The median survival for the nonresponders is twenty-four months. In contrast, the median survival for the responders has not yet been reached but is greater than forty-four months. This observation identifies the small group of patients who will respond extraordinarily well to hormonal treatment of metastatic prostate cancer.

Why do some patients demonstrate an objective treatment response and not others? It is not clear but appears unrelated to site of metastasis, type of hormonal therapy, or previous treatment. Nevertheless, an objective treatment response is an important prognostic indicator that provides optimism in the usually dismal setting of Stage D2 prostate cancer. We are continuing to investigate other parameters that may provide early prediction of prolonged survival following hormonal therapy.

\section{E. Medical Center Drive Ann Arbor, Michigan 48109-0330}

(DR. GROSSMAN)

\section{References}

1. Bayard S, Greenberg R, Showalter D, and Byar D: Comparison of treatment in prostate cancer using an exponential-type life model relating survival to concomitant information, Cancer Chemother Rep 58: 845 (1974).

2. Slack $\mathrm{N}$, et al: Criteria for evaluating patient responses to treatment modalities for prostatic cancer, Urol Clin North Am 11: 337 (1984).

3. Kozlowski J, and Grayhack J: Carcinoma of the Prostate, in Gillenwater J, et al. (Eds): Adult and Pediatric Urology, ed 2, Chicago, Year Book Medical Publishers, 1991, p 1000.

4. Schroder F: Early versus delayed endocrine treatment in metastatic prostate cancer, in Murphy G, and Khoury S (Eds): Therapeutic Progress in Urological Cancers: Proceedings of an International Symposium held in Paris, France, June 29-July 1, 1988. New York, Alan R. Liss, 1989, p 253.

5. Huggins C, Stevens R, and Hodges C: Studies on prostatic cancer: effects of castration on advanced carcinoma of the prostate gland, Arch Surg 43: 209 (1941).

6. Leuprolide Study Group: Leuprolide versus diethylstilbestrol for metastatic prostate cancer, N Engl J Med 311: 1281 (1984).

7. Peeling WB: Phase III studies to compare goserelin (Zoladex) with orchiectomy and with diethylstilbestrol in treatment of prostatic carcinoma, Urology (Suppl 5) 33: 45 (1989).

8. Crawford ED, et al: A controlled trial of leuprolide with and without flutamide in prostatic carcinoma, N Engl J Med 321: 419 (1989).

9. Murphy GP, et al: Treatment of newly diagnosed metastatic prostate cancer patients with chemotherapy agents in combination with hormones versus hormones alone, Cancer 51: 1264 (1983).

10. Bruchovsky $N$, et al: Effects of androgen withdrawal on the stem cell composition of the Shionogi carcinoma, Cancer Res 50: 2275 (1990)

11. Isaacs JT, and Kyprianou N: Development of androgenindependent tumor cells and their implication for the treatment of prostate cancer, Urol Res 15: 133 (1987).

12. Isaacs JT, Schulze H, and Coffey DS: Development of androgen resistance in prostatic cancer, Prog Clin Biol Res 243A: 21 (1987). 